\title{
Polymer End Group Modifications and Polymer Conjugations via "Click" Chemistry Employing Microreactor Technology
}

\author{
Joke Vandenbergh, ${ }^{1}$ Tiago Tura, ${ }^{2}$ Evelien Baeten, ${ }^{1}$ Thomas Junkers ${ }^{1}$ \\ ${ }^{1}$ Polymer Reaction Design Group, Institute for Materials Research (IMO-imomec), Universiteit Hasselt, Agoralaan Building D, \\ B-3590 Diepenbeek, Belgium \\ ${ }^{2}$ Escola Polytécnica da Universidade de São Paulo, Avenida Professor Luciano Gualberto, Travessa 3, n 380 Butantã, \\ São Paulo 05508-010, Brazil \\ Correspondence to: T. Junkers (E-mail: thomas.junkers@uhasselt.be)
}

Received 24 December 2013; accepted 23 January 2014; published online 6 February 2014

DOI: $10.1002 /$ pola.27112

ABSTRACT: This study presents the development of microreactor protocols for the successful continuous flow end group modification of atom transfer radical polymerization precursor polymers into azide end-capped materials and the subsequent copper-catalyzed azide alkyne click reactions with alkyne polymers, in flow. By using a microreactor, the reaction speed of the azidation of poly(butyl acrylate), poly(methyl acrylate), and polystyrene can be accelerated from hours to seconds and full end group conversion is obtained. Subsequently, coppercatalyzed click reactions are executed in a flow reactor at $80{ }^{\circ} \mathrm{C}$. Good coupling efficiencies are observed and various block copolymer combinations are prepared. Furthermore, the flow reaction can be carried out in only $40 \mathrm{~min}$, while a batch procedure takes several hours to reach completion. The results indicate that the use of a continuous flow reactor for end group modifications as well as click reactions has clear benefits towards the development and improvement of well-defined polymer materials. (c) 2014 Wiley Periodicals, Inc. J. Polym. Sci., Part A: Polym. Chem. 2014, 52, 1263-1274

KEYWORDS: atom transfer radical polymerization (ATRP); azidation; click chemistry; click reactions; diblock copolymers; microflow chemistry; microreactor technology; radical polymerization; reversible addition fragmentation chain transfer (RAFT)
INTRODUCTION Microreactor technology ${ }^{1}$ (MRT) has been demonstrated in the recent years to be an attractive and partly superior alternative over classical batch procedures ${ }^{2}$ due to its inherent advantages with regards to reaction efficiencies. Microreactors have small volumes, but allow for continuous production via constant throughput of reagents. Additionally, they enable very efficient mixing of components due to short diffusion pathways. ${ }^{3}$ The microchannel geometries also exhibit excellent thermal heat transfer so that exothermic reaction heat can be easily dissipated, ${ }^{4}$ giving rise to almost ideal isothermal reaction conditions. Furthermore, microreactors can operate at overpressures, creating the possibility to apply reaction temperatures well above the boiling point of the reaction solvent. This way, reactions can be substantially accelerated and reactions become accessible that due to limitations are impossible to carry out in batch. As a microreactor operates under very stable operating conditions, reactions become more selective and higher quality products with less byproduct formation can be obtained. ${ }^{5}$ Microreactions can be optimized by easy screening of residence times, reaction temperatures, and reagent concentra- tions. Once a process is optimized, it can then be easily upscaled by using similar reactors with longer reaction channels or by parallelization of reactors.

During the last decade, MRT has been more and more exploited in various areas of polymer synthesis. A recent review described the synthesis of linear homo- and block copolymers, as well as complex architectures such as dendrimers by applying ionic and (controlled) radical polymerization techniques in various microreactor setups. ${ }^{6} \mathrm{~A}$ number of recent papers also demonstrate the use of flow reactors for the synthesis of well-defined polymers via atom transfer radical polymerization (ATRP), ${ }^{7-11}$ nitroxidemediated polymerization, ${ }^{12,13}$ reversible addition fragmentation transfer polymerization (RAFT) ${ }^{14,15}$ and single electron transfer-living radical polymerization. ${ }^{16-19}$ Using these techniques, mostly homopolymers but also some block copolymers $^{20,21}$ could be synthesized and furthermore end group modification reactions have been described. ${ }^{22}$ It must be noted, however, that most of the aforementioned studies made use of tubular coil reactors, which are very efficient

Additional Supporting Information may be found in the online version of this article.

(c) 2014 Wiley Periodicals, Inc.

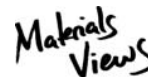




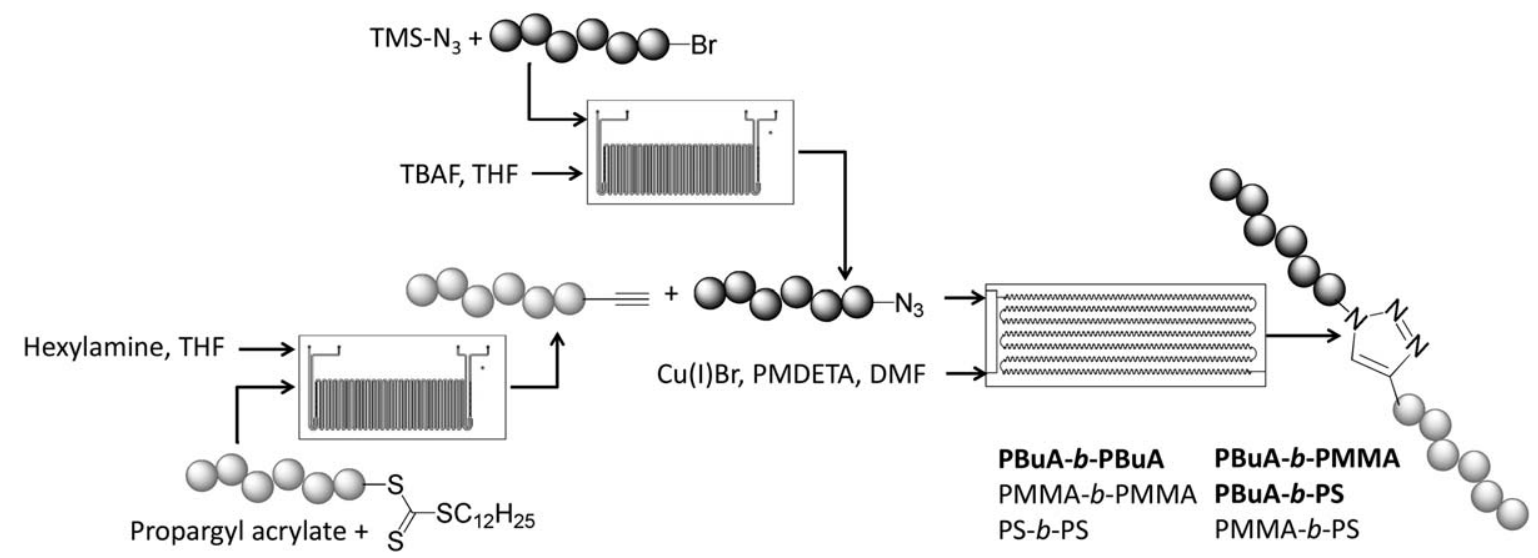

SCHEME 1 Schematic overview of end group modifications (azidation of ATRP precursors, aminolysis and thiol-ene addition of RAFT precursors) and block copolymer synthesis (CuAAC click conjugation) in continuous flow (micro)reactors. All three reactions are carried out independently and products are isolated in between.

but less flexible compared to lab-on-chip glass reactors and which may also not feature the same improvements with regards to heat transfer capabilities. Chip reactors are very versatile, and exist in many different designs and can be simply exchanged in a microreactor device setup, depending on the type of reaction under investigation.

In a previous study, we reported on the use of a glass chip microreactor for the synthesis of well-defined acrylate homopolymers and pentablock copolymers via RAFT chain extensions. ${ }^{23}$ The materials synthesized in the microreactor still exhibited narrow dispersities, which could not be achieved with polymers synthesized by a comparative batch procedure. In another study, we described the end group modification of RAFT polymers via aminolysis and in situ Michael additions with various acrylates, likewise in a glass chip microreactor. ${ }^{24}$ In batch, the reaction required a few hours to complete, but, in the microreactor, full conversion was achieved within $20 \mathrm{~min}$. Further optimization of the protocol could even accelerate the reaction to only $5 \mathrm{~min}$. In these studies, one of the acrylates used in the end group modifications was propargyl acrylate, which resulted in polymers with alkyne end groups, which are typically used in copper azide alkyne click (CuAAC) reactions. ${ }^{25}$

The current study is a direct follow-up of that work. In this article, the aim was to use MRT to perform all involved reactions for a CuAAC click reaction in flow. We thus investigated the use of MRT for the end group modification of ATRP precursor polymers via azidation of the bromo end group (Scheme 1). The azidation protocol was explored and optimized for poly( $n$-butyl acrylate) (PBuA), poly(methyl methacrylate) (PMMA), and polystyrene (PS) to generate a broad range of substrates for further CuAAC reactions. In a next step, the so-obtained azide end-capped materials were then applied in conjugation reactions with the above mentioned alkyne end-capped polymers (Scheme 1). Click reactions performed in batch and in a glass chip microflow reactor are analyzed and compared. Finally, three different block copolymers were successfully synthesized with the continuous flow process, demonstrating the versatility of the glass chip reactor for polymer-polymer conjugation reactions-a type of reaction that has to the best of our knowledge not yet been described in literature with regards to flow chemistry.

\section{EXPERIMENTAL}

\section{Materials}

n-Butyl acrylate (BuA, Acros, 99\%), methyl methacrylate (MMA, Acros, 99\%), and styrene (St, Acros, 99\%) were deinhibited over a column of activated basic alumina, before use. Copper(I) bromide ( $\mathrm{Cu}^{\mathrm{I}} \mathrm{Br}$, Acros, 98\%) was washed with acetic acid at $80{ }^{\circ} \mathrm{C}$ for $18 \mathrm{~h}$ to remove any soluble oxidized species before being filtered, washed with absolute ethanol, brought to $\mathrm{pH} 7$, then washed with ethyl ether, and then dried under vacuum. Tris(2-(dimethylamino)ethyl)amine was synthesized following a literature procedure. ${ }^{26} 1,1^{\prime}$-Azobis(isobutyronitrile) (AIBN, Sigma-Aldrich, 98\%) was recrystallized twice from ethanol before use. $N, N, N^{\prime}, N^{\prime \prime}, N^{\prime \prime}$ Pentamethyldiethylenetriamine (PMDETA, Acros, 99\%), 2,2'bipyridine (BPY, Sigma-Aldrich, 99\%), Copper(II)dibromide ( $\mathrm{Cu}^{\mathrm{II}} \mathrm{Br}_{2}$, Sigma-Aldrich, 99.9\%), methyl-2-bromopropionate (MBP, Sigma-Aldrich, 98\%), methyl $\alpha$-bromoisobutyrate (MBiB, Sigma-Aldrich, 99\%), 2-cyano-2-propyl dodecyl trithiocarbonate (CPD-TTC) (Sigma-Aldrich, 97\%), trimethylsilyl azide (TMS- $\mathrm{N}_{3}$, Sigma-Aldrich, 95\%), tetrabutylammonium fluoride solution (TBAF, Sigma-Aldrich, 1.0 M in THF), hexyl amine (Sigma-Aldrich, 99\%), and propargyl acrylate (SigmaAldrich, 98\%) were used as received. All solvents used are obtained from commercial sources (Acros and Sigma-Aldrich) and used without further purification.

\section{Flow Reactor Setups}

Microreactions were performed in the Labtrix ${ }^{\circledR}$ Start R2.2 system (Chemtrix BV, NL), fitted with a glass microreactor (3227, internal volume $=19.5 \mu \mathrm{L}$, channel dimensions: width $\times$ depth $=300 \times 120 \mu \mathrm{m}^{2}$ ) containing an SOR-2 static micromixer. The system was maintained at 20 bar of backpressure by means of a preset ultralow dead-volume backpressure regulator (Upchurch Scientific), in order to prevent 
boiling of the reactants and solvent system when temperatures above the atmospheric boiling point were employed. Reactant solutions were introduced into the reactor through three 1-mL gastight syringes (SGE) capable of delivering three solutions at flow rates between 0.1 and $25 \mu \mathrm{L} \mathrm{min}{ }^{-1}$. The flow rates were controlled via two syringe pumps (Chemyx), and the reactor temperature was controlled via a thermoelectric cooler temperature controller MTTC1410 (Melcor Thermal Solutions, temperature range -15 to $195^{\circ} \mathrm{C}$ ).

Click reactions were performed in a custom-built reactor system (Uniqsis, UK), fitted with a glass microreactor (internal volume $=2 \mathrm{~mL}$, channel internal diameter $=1 \mathrm{~mm}$ ) with active mixing geometry channels and a backpressure regulator (6.9 bar). Reactant solutions were introduced into the reactor through two 1 - or $2.5-\mathrm{mL}$ gastight syringes (SGE) capable of delivering two solutions at flow rates between 25 and $250 \mu \mathrm{L} \min ^{-1}$. The flow rates were controlled via a syringe pump (Chemyx), and the reactor temperature was controlled via a conventional hotplate equipped with a temperature controller (IKA Laboratory Equipment, RCT basic, temperature range $20-150{ }^{\circ} \mathrm{C}$ ).

\section{Characterization}

NMR spectra were recorded in deuterated chloroform with a Varian Inova 300 spectrometer at $300 \mathrm{MHz}$ for ${ }^{1} \mathrm{H}$ NMR and at $75 \mathrm{MHz}$ for ${ }^{13} \mathrm{C} \mathrm{NMR}$, applying a pulse delay of $12 \mathrm{~s}$ using a Varian probe (5 mm-4-nucleus AutoSWPFG). FTIR spectra were collected with a Brucker Tensor 27 FTIR spectrophotometer (nominal resolution $4 \mathrm{~cm}^{-1}$ ). Analysis of the MWDs of the polymer samples were performed on a Tosoh EcoSEC operated by PSS WinGPC software, equipped with a PLgel 5.0$\mu \mathrm{m}$ guard column $(50 \times 8 \mathrm{~mm})$, followed by three PLgel 5 $\mu \mathrm{m}$ mixed-C columns $(300 \times 8 \mathrm{~mm})$ and a differential refractive index detector using THF as the eluent at $40{ }^{\circ} \mathrm{C}$ with a flow rate of $1 \mathrm{~mL} \mathrm{~min}{ }^{-1}$. The SEC system was calibrated using linear narrow PS standards ranging from 474 to $7.5 \times 10^{6} \mathrm{~g}$ $\mathrm{mol}^{-1} \mathrm{PS}\left(K=14.1 \times 10^{-5} \mathrm{dLg}^{-1}\right.$ and $\left.\alpha=0.70\right)$, and toluene as a flow marker. ESI-MS was performed using an LCQ Fleet mass spectrometer (ThermoFischer Scientific) equipped with an atmospheric pressure ionization source operating in the nebulizer assisted electro spray mode. The instrument was calibrated in the $m / z$ range 220-2000 using a standard solution containing caffeine, MRFA and Ultramark 1621. A constant spray voltage of $5 \mathrm{kV}$ was used and nitrogen at a dimensionless auxiliary gas flow-rate of 3 and a dimensionless sheath gas flow-rate of 3 were applied. The capillary voltage, the tube lens offset voltage and the capillary temperature were set to $25,120 \mathrm{~V}$, and $275{ }^{\circ} \mathrm{C}$, respectively. A $250-\mu \mathrm{L}$ aliquot of a polymer solution with concentration of $10 \mu \mathrm{g} \mathrm{mL}^{-1}$ was injected. A mixture of THF and methanol (THF:MeOH = 3:2), all HPLC grade, were used as solvent.

\section{Synthesis}

\section{ATRP Polymerization of BuA}

PBuA-Br (1) polymer with $M_{\mathrm{n}}=1100 \mathrm{~g} \mathrm{~mol}^{-1}$ and $\emptyset=1.14$ (by THF-SEC, $K=12 \times 10^{-3}, \alpha=0.7$ ) and a $95 \%$ Br-end group functionality (by ESI-MS) was synthesized according to a literature procedure. ${ }^{27}$

$[\mathrm{BuA}]_{0}:[\mathrm{MBP}]_{0}:[\mathrm{Cu}(\mathrm{I}) \mathrm{Br}]_{0}:[\mathrm{PMDETA}]_{0}=80: 1: 1.1: 2.2$.

Conversion $=12 \%, M_{\mathrm{n}}^{\text {th }}=1397 \mathrm{~g} \mathrm{~mol}^{-1}$. Also second batch of PBuA-Br (1) polymer with $M_{\mathrm{n}}=1900 \mathrm{~g} \mathrm{~mol}^{-1}$ and $Ð=1.30$ was made with the same procedure. Conversion $=15 \%, M_{\mathrm{n}}^{\text {th }}=1705 \mathrm{~g} \mathrm{~mol}^{-1}$.

\section{ATRP Polymerization of MMA}

PMMA-Br (2) polymer with $M_{\mathrm{n}}=1900 \mathrm{~g} \mathrm{~mol}^{-1}$ and $D=1.33$ (by THF-SEC, $K=13 \times 10^{-3}, \alpha=0.688$ ) and a $95 \%$ Br-end group functionality (by ESI-MS) was synthesized according to an adapted literature procedure. ${ }^{28}$

$[\mathrm{MMA}]_{0}:[\mathrm{MBiB}]_{0}:[\mathrm{Cu}(\mathrm{I}) \mathrm{Br}]_{0}:\left[\mathrm{Cu}(\mathrm{II}) \mathrm{Br}_{2}\right]_{0}:[\mathrm{BPY}]_{0}=10: 1: 0.1:$ $0.01: 0.25$.

Reaction conditions: 1 h, $50 \quad{ }^{\circ} \mathrm{C}$. Conversion $=48 \%$, $M_{\mathrm{n}}^{\text {th }}=647 \mathrm{~g} \mathrm{~mol}^{-1}$.

\section{ATRP Polymerization of St}

The purified $\mathrm{Cu}(\mathrm{I}) \mathrm{Br}(2.710 \mathrm{mmol}, 390 \mathrm{mg}, 1.1$ equiv) was added together with $0.173 \mathrm{~mol}$ (18 g, 70 equiv) of the monomer St and $2.470 \mathrm{mmol}$ (416 mg, 1 equiv) of MBP initiator under inert atmosphere into a sealed Schlenk tube. The Schlenk tube was subjected to three freeze-pump-thaw cycles to remove residual oxygen, after which it was filled with a nitrogen atmosphere. In a separate vial, a mixture of EtOAc ( $2 \mathrm{~mL}, 9 \mathrm{vol} \%$ ) and $5.430 \mathrm{mmol}$ (950 mg, 2.2 equiv) of PMDETA ligand was degassed likewise. The reaction mixture in the Schlenk was heated up to $80{ }^{\circ} \mathrm{C}$ in an oil bath. Subsequently, the polymerization is started by adding the degassed solvent-initiator mixture. After a reaction time of $90 \mathrm{~min}$, the polymerization was stopped by cooling in liquid nitrogen and a NMR sample was taken to determine a conversion of $35 \%$. The polymer/monomer mixture was dissolved in THF, and the copper catalyst was removed by passing the diluted reaction mixture over basic alumina. Afterward, the excess of solvent and residual monomer was evaporated, yielding $6.3 \mathrm{~g}$ of $\mathrm{PS}-\mathrm{Br}$ (3) polymer with $M_{\mathrm{n}}=3100 \mathrm{~g} \mathrm{~mol}^{-1}$ and $D=1.15$ (by THF-SEC, $K=14 \times$ $10^{-3}, \alpha=0.7$ ). Conversion $=35 \%, M_{\mathrm{n}}^{\text {th }}=2719 \mathrm{~g} \mathrm{~mol}^{-1}$.

\section{Azidation of ATRP Polymers in a Continuous-Flow Microreactor}

In a typical procedure, 1 equiv of the ATRP polymer $\mathbf{1}, \mathbf{2}$ or 3 , and 3 equiv of TMS- $\mathrm{N}_{3}$ were dissolved in THF $(1 \mathrm{~mL} / 100$ mg polymer) in a glass vial. In another vial, 3 equiv of the $1 \mathrm{M}$ TBAF solution was diluted with THF (until an equal volume as for the polymer solution was reached). Two 1-mL gastight syringes were filled with the two reagent solutions. By using the Labtrix® Start R2.2 system, fitted with a glass microreactor $(3227$, reactor volume $=19.5 \mu \mathrm{L}$ ), the solution was pumped into the reactor. Both reaction times and reaction temperatures were screened by collecting reaction samples which were analyzed with ESI-MS immediately after collecting to determine end group conversion of $\mathrm{PBuA}-\mathrm{N}_{3}$ 
TABLE 1 Reaction Conditions and ESI-MS Species Results for Azidation of PBuA-Br (1) in Continuous-Flow Microreactor

\begin{tabular}{|c|c|c|c|c|c|}
\hline Entry & $\begin{array}{l}\text { Reaction } \\
\text { Time } \\
\text { (min) }\end{array}$ & $\begin{array}{l}\text { Reaction } \\
\text { Temp. } \\
\left({ }^{\circ} \mathrm{C}\right)\end{array}$ & $\begin{array}{l}\text { TMS- }_{3} \\
\text { (and TBAF) } \\
\text { (equiv) }\end{array}$ & $\begin{array}{l}\text { ATRP- } \\
\text { polymer } \\
(\%)\end{array}$ & $\begin{array}{l}\mathrm{N}_{3^{-}} \\
\text {polymer } \\
(\%)\end{array}$ \\
\hline 1 & 20 & 20 & 1.5 & 33 & 67 \\
\hline 2 & 20 & 40 & 1.5 & 26 & 74 \\
\hline 3 & 20 & 60 & 1.5 & 22 & 78 \\
\hline 4 & 20 & 80 & 1.5 & 21 & 79 \\
\hline 5 & 20 & 100 & 1.5 & 21 & 79 \\
\hline 6 & 10 & 100 & 1.5 & 22 & 78 \\
\hline 7 & 5 & 100 & 1.5 & 27 & 73 \\
\hline 8 & 20 & 60 & 10 & I & $\geq 95$ \\
\hline 9 & 20 & 80 & 10 & 1 & $\geq 95$ \\
\hline 10 & 20 & 100 & 10 & 1 & $\geq 95$ \\
\hline 11 & 10 & 100 & 10 & 1 & $\geq 95$ \\
\hline 12 & 5 & 100 & 10 & 1 & $\geq 95$ \\
\hline 13 & 20 & 100 & 3 & 1 & $\geq 95$ \\
\hline 14 & 10 & 100 & 3 & 1 & $\geq 95$ \\
\hline 15 & 5 & 100 & 3 & 1 & $\geq 95$ \\
\hline 16 & 2 & 100 & 3 & 1 & $\geq 95$ \\
\hline 17 & 1 & 100 & 3 & 1 & $\geq 95$ \\
\hline 18 & 0.5 & 100 & 3 & I & $\geq 95$ \\
\hline 19 & 0.25 & 100 & 3 & 1 & $\geq 95$ \\
\hline 20 & 0.25 & 80 & 3 & I & $\geq 95$ \\
\hline 21 & 0.25 & 60 & 3 & 10 & 90 \\
\hline 22 & 0.25 & 40 & 3 & 38 & 62 \\
\hline 23 & 0.25 & 20 & 3 & 63 & 37 \\
\hline
\end{tabular}

(4), PMMA-N $\mathrm{N}_{3}$ (5). For PS- $\mathrm{N}_{3}$ (6), the samples were analyzed with FTIR and NMR to determine end group conversion. The results are displayed in Tables 1 and 2 and Figures 1-4. The collected samples were purified from the residual TMS- $\mathrm{N}_{3}$ and TBAF by filtering over basic alumina and silica, followed by evaporation of the solvent.

\section{RAFT Polymerization of BuA}

PBuA-RAFT (7) polymer with $M_{\mathrm{n}}=1900 \mathrm{~g} \mathrm{~mol}^{-1}$ and $Ð=1.16$ (by THF-SEC, $K=12 \times 10^{-3}, \alpha=0.7$ ) and a $95 \%$ RAFT-end group functionality (by ESI-MS) was synthesized according to an adapted literature procedure. ${ }^{24}$

$[\mathrm{BuA}]_{0}:[\mathrm{CPD}-\mathrm{TTC}]_{0}:[\mathrm{AIBN}]_{0}=80: 1: 0.1$. Reaction conditions: $80{ }^{\circ} \mathrm{C}, 20 \mathrm{~min}$.

Conversion $=19 \%, M_{\mathrm{n}}^{\text {th }}=2294 \mathrm{~g} \mathrm{~mol}^{-1}$. Also, second batch of PBuA-RAFT (7) polymer with $M_{\mathrm{n}}=3400 \mathrm{~g} \mathrm{~mol}^{-1}$ and $Ð=1.11$ was made with the same procedure, but with a reaction time of $25 \mathrm{~min}$. Conversion $=31 \%, M_{\mathrm{n}}^{\text {th }}=3524 \mathrm{~g} \mathrm{~mol}^{-1}$.

\section{RAFT Polymerization of MMA}

About $0.040 \mathrm{~mol}$ (4 g, 80 equiv) of the monomer MMA, $0.049 \mathrm{mmol}$ (0.008 g, 0.1 equiv) of AIBN, and $0.499 \mathrm{mmol}$ ( $0.172 \mathrm{~g}, 1$ equiv) of CPD-TTC RAFT agent were added into a sealed Schlenk tube. The Schlenk tube was subjected to three freeze-pump-thaw cycles, after which the mixture was polymerized inside a glove box for $25 \mathrm{~min}$ at $80{ }^{\circ} \mathrm{C}$. Subsequently, the reaction mixture was poured into an aluminium pan and quenched with hydroquinone/MeOH. Afterward, the residual monomer was evaporated, yielding $0.336 \mathrm{~g}$ of PMMA-RAFT (8) polymer with $M_{\mathrm{n}}=2000 \mathrm{~g} \mathrm{~mol}^{-1}$ and $Ð=1.30$ (by THF-SEC, $K=13 \times 10^{-3}, \alpha=0.688$ ) and a $95 \%$ RAFT-end group functionality (by ESI-MS). Conversion $=9 \%$, $M_{\mathrm{n}}^{\text {th }}=1066 \mathrm{~g} \mathrm{~mol}^{-1}$.

\section{RAFT Polymerization of St}

About $0.038 \mathrm{~mol}$ ( $4 \mathrm{~g}, 100$ equiv) of the monomer St, 0.038 mmol ( $0.006 \mathrm{~g}, 0.1$ equiv) of AIBN, and $0.384 \mathrm{mmol}(0.133 \mathrm{~g}$, 1 equiv) of CPD-TTC RAFT agent were added into a sealed Schlenk tube. The Schlenk tube was subjected to three freezepump-thaw cycles, after which the mixture was polymerized inside a glove box for $5 \mathrm{~h}$ at $80^{\circ} \mathrm{C}$. Subsequently, the reaction mixture was poured into an aluminium pan and quenched with Hydroquinone/MeOH. Afterward, the residual monomer was evaporated, yielding $0.500 \mathrm{~g}$ of PS-RAFT (9) polymer with $M_{\mathrm{n}}=2200 \mathrm{~g} \mathrm{~mol}^{-1}$ and $\emptyset=1.10$ (by THF-SEC, $K=14 \times$ $\left.10^{-3}, \alpha=0.7\right)$. Conversion $=14 \%, M_{\mathrm{n}}^{\text {th }}=2140 \mathrm{~g} \mathrm{~mol}^{-1}$.

\section{Synthesis of Alkyne End-Capped Polymers via Aminolysis and Thiol-Ene Click Reaction}

RAFT polymer 7, 8, or 9 (1 equiv) was dissolved in THF ( 9 $\mathrm{mL} / \mathrm{g}$ ) in a glass vial. Subsequently, propargyl acrylate (10 equiv) was added and the mixture was degassed by nitrogen purging for $15 \mathrm{~min}$ after which the vial was inserted in the glovebox. Afterward, a degassed mixture of hexylamine (10 equiv) in THF $(0.68 \mathrm{M})$ was added and the mixture was reacted for $3 \mathrm{~h}$ at room temperature, by which it turned colourless. Subsequently, the reaction mixture was poured into an aluminium pan and the excess of solvent was evaporated, yielding PBuA-alkyne (10), PMMA-alkyne (11), and PSalkyne (12). The polymers were purified by recycling GPC or

TABLE 2 Reaction Conditions and ESI-MS Species Results for Azidation of PMMA-Br (2) in Continuous-Flow Microreactor

Reaction Reaction ATRP- $\quad \mathrm{N}_{3^{-}} \quad$ Elim.

Time (min) Temp. $\left({ }^{\circ} \mathrm{C}\right)$ polymer $(\%)$ polymer $(\%)$ polymer $(\%)$

$\begin{array}{llllll}1 & 0.25 & 80 & \geq 95 & - & - \\ 2 & 0.5 & 80 & \geq 95 & - & - \\ 3 & 1 & 80 & \geq 95 & - & - \\ 4 & 1 & 100 & 58 & 28 & 14 \\ 5 & 1 & 120 & 22 & 54 & 24 \\ 6 & 20 & 80 & 60 & 29 & 11 \\ 7 & 20 & 100 & 31 & 50 & 19 \\ 8 & 20 & 120 & 21 & 55 & 24 \\ 9^{\mathrm{a}} & 1,200 & 20 & 22 & 57 & 21 \\ 10^{\mathrm{b}} & 180 & 20 & 43 & 44 & 13\end{array}$

In all cases, 3 equiv. of TMS- $\mathrm{N}_{3}$ and TBAF were used.

${ }^{a}$ Batch, TMS- $\mathrm{N}_{3}$.

b Batch, $\mathrm{NaN}_{3}$. 

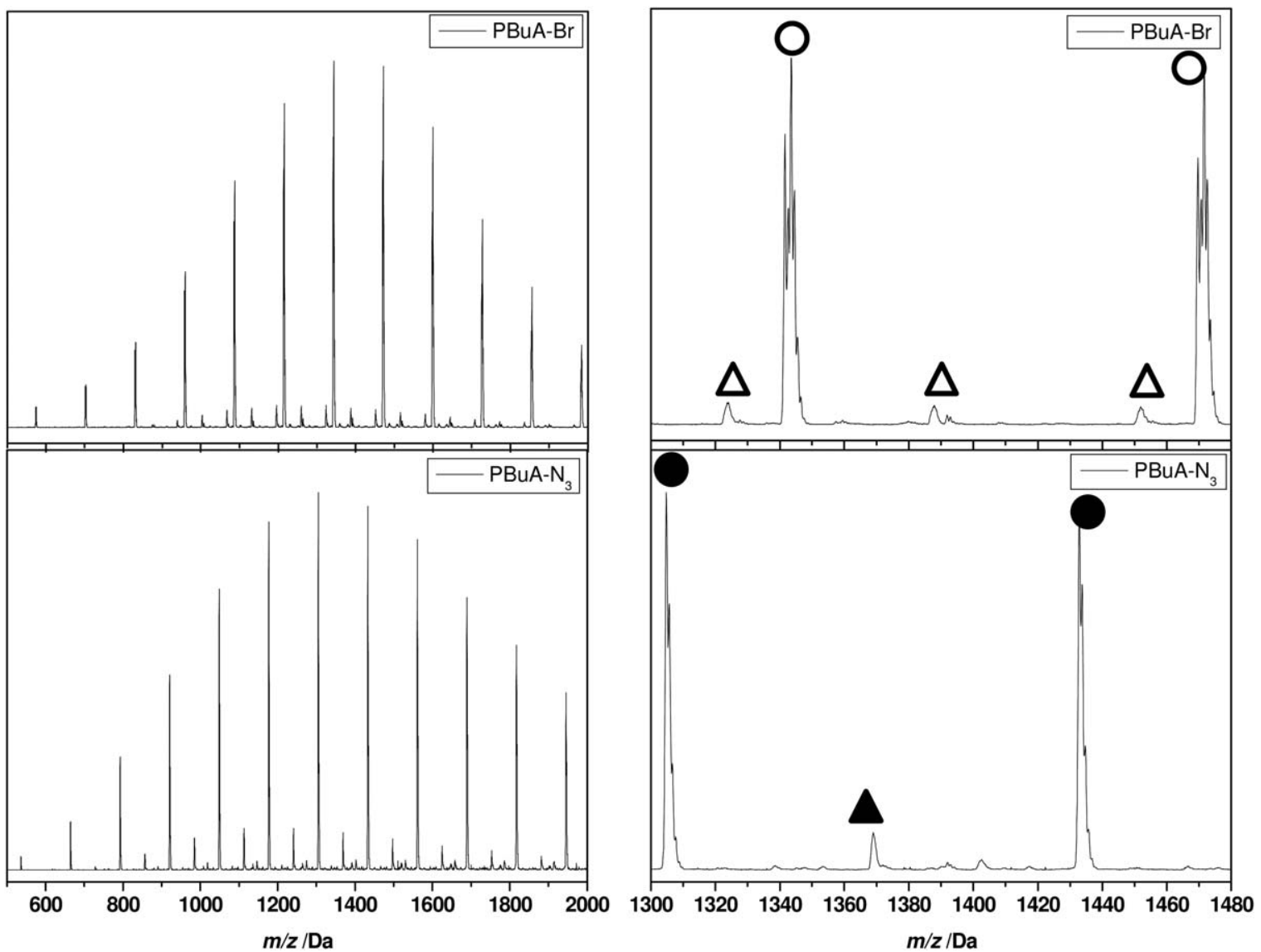

FIGURE 1 ESI-MS spectra of PBuA-Br (1) and PBuA-N $\mathrm{N}_{3}$ (4). Left: full MS spectra. Right: spectra of single-monomer repeating units (circles represent single charged species; triangles represent double charged species).

by precipitation into a nonsolvent. The dried polymers (10 and 11) were analyzed with ESI-MS to determine the end group conversion. Besides this bulk procedure, the end group conversions can also be executed in a continuous-flow microreactor, as described in a previous study. ${ }^{24}$

\section{Polymer-Polymer Conjugation via CuAAC Click Reaction in Batch}

An azide end-capped polymer (1 equiv) and an alkyne endcapped polymer (1 equiv) were dissolved in DMF ( $1 \mathrm{~mL} / 100 \mathrm{mg}$ total polymer content) in a glass vial. In another glass vial, $\mathrm{Cu}(\mathrm{I}) \mathrm{Br}$ (1 equiv) and PMDETA (2 equiv) were dissolved in THF (equal amount to polymer solution). Both solutions were degassed and inserted in the glovebox. The $\mathrm{Cu}(\mathrm{I})$ solution was added to the polymer solution, and the reaction mixture was stirred for $3 \mathrm{~h}$ at R.T. Subsequently, the reaction mixture was taken out of the glovebox, filtered over basic alumina, and the solvent was evaporated by a nitrogen flush. For all reactions, the resulting clicked block copolymers were analyzed with THF-SEC. The results for PBuA- $b$-PBuA (13B), PBuA- $b$-PMMA (14B), and $\mathrm{PBuA}-b$-PS (15B) are displayed in Table 3 and Figures 7 and 8.

Polymer-Polymer Conjugation via CUAAC Click Reaction in Continuous-Flow Reactor

An azide end-capped polymer (1 equiv) and an alkyne endcapped polymer ( 1 equiv) were dissolved in DMF ( $1 \mathrm{~mL} / 100$ mg total polymer content) in a glass vial. In another glass vial, $\mathrm{Cu}(\mathrm{I}) \mathrm{Br}$ ( 1 equiv) and PMDETA (2 equiv) were dissolved in THF (equal amount to polymer solution). Both solutions were degassed and inserted in the glovebox. Two 1-mL gastight syringes were filled with the two reagent solutions. By using the Uniqsis ${ }^{\circledR}$ system, fitted with a glass microreactor (reactor volume $=2 \mathrm{~mL}$ ), the solution was pumped at a total flow rate of $50 \mu \mathrm{L} / \mathrm{min}$ (residence time $40 \mathrm{~min}$ ) into the reactor which had a temperature of $80{ }^{\circ} \mathrm{C}$. After insertion of the reagent solutions, the empty syringes were immediately refilled with DMF and reconnected to the reactor to reestablish constant flow. The reaction mixture was collected, filtered over basic alumina and the solvent was evaporated by a nitrogen flush. For all reactions, the resulting clicked block copolymers were analyzed with THF-SEC. The results for PBuA- $b$-PBuA (13F), PBuA- $b$-PMMA (14F), and PBuA- $b$-PS (15F) are displayed in Table 3 and Figures 7 and 8.

\section{RESULTS AND DISCUSSION}

\section{Azidation of ATRP Precursors}

The first reaction examined in the microreactor in the framework of this study was the azidation of bromo end-capped ATRP polymers. Three different polymers were synthesized via ATRP in batch, for example, PBuA-Br (1), PMMA-Br (2) 

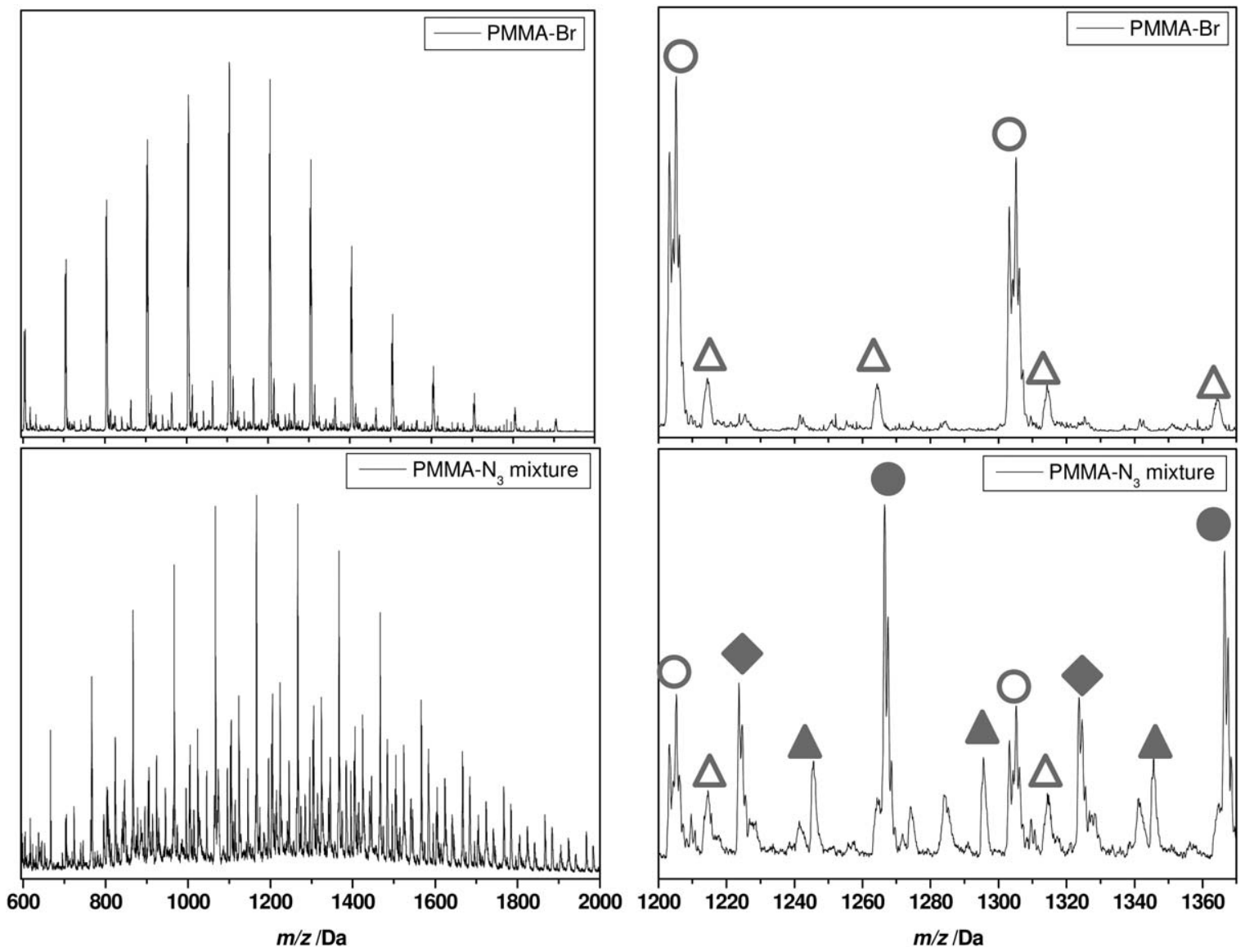

FIGURE 2 ESI-MS spectra of PMMA-Br (2) and PMMA-N $\mathrm{N}_{3}$ mixture (5). Left: full MS spectra. Right: spectra of single-monomer repeating units (circles and rhombus represent single charged species; triangles represent double charged species).

and PS-Br (3). It should be noted that ATRP polymerization in flow is-despite the difficulty to avoid copper precipitates during the reaction that would lead to blockage of the reactor channels-possible and had been demonstrated before. $^{7,9-11}$ After isolation of the polymers, the end group conversion into azide end-capped materials was studied. Usually, in a batch procedure, solid sodium azide in DMF is used to convert the bromo end group of an ATRP polymer.
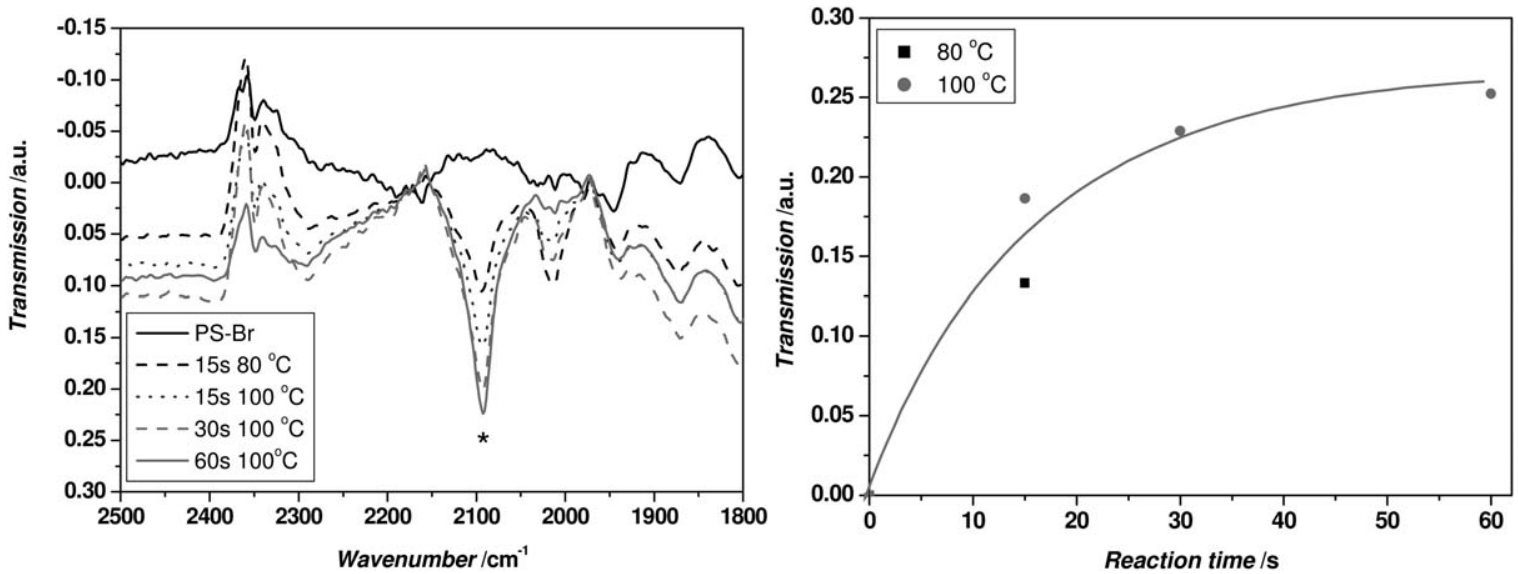

FIGURE 3 Left: FTIR spectra of PS-Br (3) and PS- $\mathrm{N}_{3}(6)$, after reaction with different conditions in continuous-flow microreactor, region between 2500 and $1800 \mathrm{~cm}^{-1}$. The vibration marked with an asterisk $\left(2093 \mathrm{~cm}^{-1}\right)$ results from the formation of the azide end group. For full spectra, see Supporting Information. Right: FTIR transmission of azide vibration band in function of increased reaction time. 


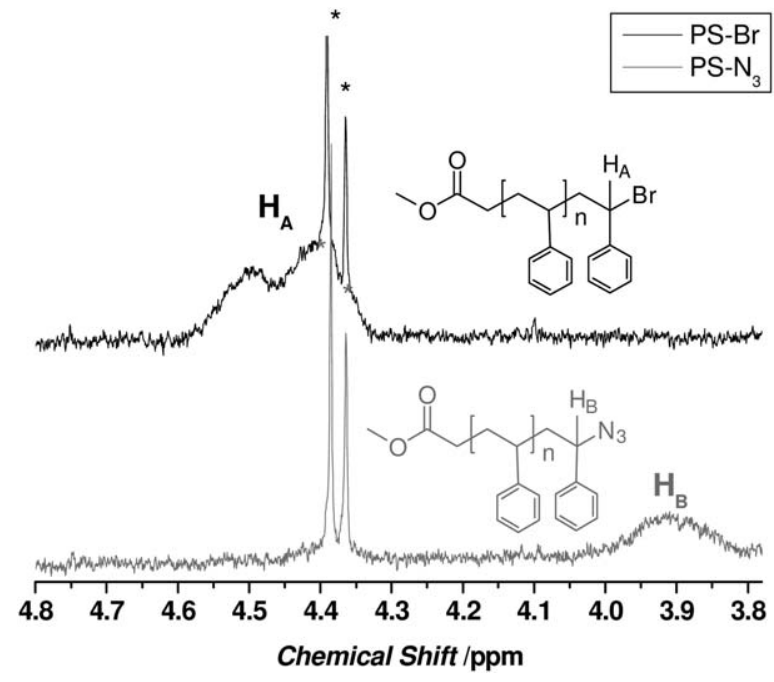

FIGURE $4{ }^{1} \mathrm{H}$ NMR spectra of PS-Br (3) and PS- $\mathrm{N}_{3}(6)$, region between 4.8 and 3.8 ppm. Resonances marked with an asterisk result from a small impurity. For full spectra, see Supporting Information.

However, such reaction goes along with a precipitation of salt particles, thus providing heterogeneous reaction mixtures that are unsuitable for MRT adaption. Precipitates would inevitably lead to blocking of the microchannels and hence damage the microreactor setup. In order to circumvent this problem, the reaction procedure had to be adapted in a way that only liquid reagents were used. To reach this goal, the solid sodium azide was replaced by liquid trimethylsilyl azide $\left(\mathrm{TMS}-\mathrm{N}_{3}\right){ }^{29}$ TMS-azide as such is not overly reactive, the protecting group can, however, be removed by adding a solution of tetrabutylammonium fluoride (TBAF) in THF, forming $\mathrm{H}-\mathrm{N}_{3}$ as a reactive intermediate. Thus, for the azidation in flow, a solution of a PBuA-Br (1) and TMS- $\mathrm{N}_{3}$ in THF were entered in one microreactor inlet while a second solution of TBAF in THF was infused in the second inlet. Reaction conditions such as reagent concentrations, reaction time, and reaction temperature could then be easily screened in the microreactor and the results are summarized in Table 1.

As the microreactor operates at a pressure of 20 bar and no free air volumes are present in the microchannels, the azidation reaction can be carried out at elevated temperatures above the solvents normal boiling point. This is prohibitive in a classical batch process, due to severe safety issues such as explosion risks and formation of extremely toxic $\mathrm{HN}_{3}$ gases, but does not pose problems in microreactions. Because of the possibility to use increased reaction temperatures in the microreactor, combined with very rapid mixing and efficient heat transfer, the azidation reaction could be accelerated considerably. In batch, the end groups are commonly completely converted within approximately $3 \mathrm{~h}$ at room temperature. In the microreactor on the other hand, by using 3 equiv of TMS- $\mathrm{N}_{3}$ and TBAF at a reaction temperature of $80{ }^{\circ} \mathrm{C}$, full conversion could be reached within only $15 \mathrm{~s}$

TABLE 3 SEC Results of Azide and Alkyne End-Capped Precursor Polymers and of Resulting Block Copolymers After CuAAC Click Reactions in Batch (3 h) or Flow (40 min)

\begin{tabular}{|c|c|c|c|c|c|c|}
\hline Polymers & $M_{\mathrm{n}}\left(\mathrm{g} \mathrm{mol}^{-1}\right)^{\mathrm{a}}$ & $D$ & Reaction & Block copolymer & $M_{\mathrm{n}}\left(\mathrm{g} \mathrm{mol}^{-1}\right)^{\mathrm{a}}$ & $D$ \\
\hline $\mathrm{PBuA}-\mathrm{N}_{3}$ & 2,000 & 1.43 & Batch & PBuA- $b-\mathrm{PBuA}(\mathrm{B})$ & 5,100 & 1.15 \\
\hline PBuA-alkyne & 3,400 & 1.14 & & & & \\
\hline PBuA-N 3 & 2,000 & 1.34 & Flow & PBuA- $b$-PBuA (F) & 3,000 & 1.48 \\
\hline PBuA-alkyne & 1,600 & 1.18 & & & & \\
\hline PBuA- $N_{3}$ & 2,000 & 1.34 & Batch & PBuA- $b$-PMMA (B) & 3,600 & 1.35 \\
\hline PMMA-alkyne & 2,000 & 1.26 & & & & \\
\hline $\mathrm{PBuA}-\mathrm{N}_{3}$ & 2,000 & 1.34 & Flow & PBuA- $b$-PMMA (F) & 3,600 & 1.26 \\
\hline PMMA-alkyne & 2,000 & 1.26 & & & & \\
\hline PBuA-N 3 & 1,200 & 1.15 & Batch & PBuA-b-PS (B) & 2,500 & 1.28 \\
\hline PS-alkyne & 1,900 & 1.20 & & & & \\
\hline PBuA-N 3 & 1,200 & 1.15 & Flow & PBuA- $b$-PS (F) & 2,500 & 1.31 \\
\hline PS-alkyne & 1,900 & 1.20 & & & & \\
\hline PS- $N_{3}$ & 3,400 & 1.11 & Batch & PS- $b$-PBuA (B) & 6,600 & 1.27 \\
\hline PBuA-alkyne & 5,300 & 1.10 & & & & \\
\hline$P S-N_{3}$ & 3,400 & 1.11 & Batch & PS- $b$-PMMA (B) & 4,200 & 1.29 \\
\hline PMMA-alkyne & 2,000 & 1.30 & & & & \\
\hline PS- $N_{3}$ & 3,400 & 1.11 & Batch & PS- $b$-PS (B) & 4,000 & 1.23 \\
\hline PS-alkyne & 2,100 & 1.10 & & & & \\
\hline
\end{tabular}

${ }^{a}$ For every polymer, its corresponding Mark-Houwink-Kuhn-Sakurada (MHKS) $\mathrm{K}$ and $\alpha$ parameters were used to determine molar mass (see Experimental section). For PBuA- $b$-PMMA and PS- $b$-PMMA, MHKS parameters of PMMA were applied. For PBuA- $b$-PS and PS- $b$-PBuA, MHKS parameters of PBuA were applied. 
as is evident from the series of experiments given in the table. Although also higher reaction temperatures lead to full conversion within a similar timeframe, $80{ }^{\circ} \mathrm{C}$ was chosen as the optimal temperature since less energy is required to heat the reactor. Furthermore, although higher excesses of TMS- $\mathrm{N}_{3}$ and TBAF could be used, an excess of 3 equiv was sufficient for full end group conversion. Although the effect of these economizations are negligible in a small microreactor, it has a substantial impact when the process would be upscaled to an industrial scale, where saving energy and feed stocks leads to more cost-efficient processes.

In the current procedure, conversions of end groups were followed by electrospray ionization mass spectrometry (ESIMS) directly after sample collection and dilution in a mixture of THF and $\mathrm{MeOH}$ (see Figure 1 for representative mass spectra). As can be seen from Figure 1, the initial bromo end groups of the poly(butyl acrylate) are quantitatively converted into azide end groups. The only minor peaks observable (marked with triangles in the figure) result from double charging underpinning the overall high purity of the samples. A comprehensive table of exact masses of all detected species can be found in the Supporting Information.

After optimization of the azidation protocol for PBuA, the same reaction was tested on PMMA-Br (2). Again, 3 equiv of TMS- $\mathrm{N}_{3}$ and TBAF were used in the microreactor and reaction temperature and reaction time were screened. The results are displayed in Table 2. Also, all collected samples were instantly analyzed with ESI-MS (Fig. 2). From the table, it is immediately obvious that the azidation reaction onto PMMA is slower than for PBuA. After a reaction time of 1 min at $80{ }^{\circ} \mathrm{C}$, the collected samples still contain only PMMABr starting material. At $120{ }^{\circ} \mathrm{C}, 54 \%$ of PMMA- $\mathrm{N}_{3}$ conversion was observed, and this percentage could not be further enhanced by applying longer reaction times (20 min). To test if this effect was specific to the flow process, also batch reactions were performed with the same reagents, whereby similar limiting results were obtained. Furthermore, comparable results were even obtained for batch reactions using sodium azide, demonstrating that the described difficulty is not specific to the otherwise employed TMS azide.

Besides the desired product PMMA- $\mathrm{N}_{3}$, the collected samples also contained starting PMMA-Br and a considerable amount of unsaturated end group-eliminated polymer chains. Occurrence of such product was limiting the accessible yields for both the MRT as well as the batch reactions. (For structural assignments of the species observed in ESI-MS, see Supporting Information.) Indeed, it was reported previously, that the bromo end groups of PMMA synthesized by ATRP are quite thermally unstable and can be eliminated. ${ }^{30}$ Furthermore, another report even described the deliberate elimination of ATRP PMMA polymer by TBAF $^{31}$ Since similar effects were observed in our study, it was concluded that complete azidation end group conversion of PMMA-Br is impossible using such protocol. Therefore, the resulting product was not applied in any further CuAAC click reactions.
The azidation protocol was also tested on PS-Br (3). Again, 3 equiv excess of TMS- $\mathrm{N}_{3}$ and TBAF were used and the reaction conditions in the microreactor were optimized. In this case, the collected PS samples were not analyzed by ESI-MS, due to the inherent difficulties associated with end group determination of the apolar PS by this technique. ${ }^{32}$ Instead, collected samples were quenched after reaction by precipitation in $\mathrm{MeOH}$ and subsequently analyzed via infrared spectroscopy (FTIR) (Fig. 3). Upon reaction, a new vibration band at $2093 \mathrm{~cm}^{-1}$ appears in the spectrum, which is typically associated with the formation of the azide end groups. ${ }^{33}$ When the intensity of this vibration is plotted against increasing reaction times (see also Fig. 3), it becomes obvious that the azidation reaction is more or less completed within $1 \mathrm{~min}$ at $100{ }^{\circ} \mathrm{C}$. Reaction at $80{ }^{\circ} \mathrm{C}$ also showed some success, however, a significant rate increase could be observed at $100{ }^{\circ} \mathrm{C}$ as is also indicated by the data.

As the IR spectra could only show the appearance of the characteristic azide peak, further analysis was required to check for the quantitative disappearance of the original bromide. Thus, the collected samples were also analyzed with ${ }^{1} \mathrm{H}$ NMR (see Fig. 4 for characteristic ppm region, full spectra can be found in the Supporting Information). The resonance at $4.6-4.35 \mathrm{ppm}$, which is typically attributed to the hydrogen on the carbon atom next to the bromine group, ${ }^{34}$ shifts completely to $4.0-3.8 \mathrm{ppm}$, upon formation of the azide end group, indicating again the successful and also quantitative end group conversion of the PS polymer.

\section{Formation of Alkyne End-Capped Polymers}

Since the goal was to use the azide end-capped polymers in polymer-polymer conjugation CuAAC click reactions, alkyne end-capped polymers had also to be provided. To this end, PBuA, PMMA, and PS precursors were synthesized via RAFT, using a trithiocarbonate chain transfer agent. The trithiocarbonate end groups of the resulting polymers were subsequently modified via aminolysis with hexylamine followed by in situ thiol-ene Michael additions with propargyl acrylate, resulting in alkyne end-capped polymers.

Although the reactions in this particular study were executed in batch mode, also MRT can be used to effectively perform this reaction sequence as we had demonstrated before. ${ }^{23,24}$ For PBuA and PMMA, the ESI-MS analysis of the starting RAFT polymers and resulting alkyne polymers used in the current study is displayed in Figures 5 and 6. In both cases, practically full conversion of the RAFT end groups into alkyne end groups was achieved. Again, for PS, no ESI-MS could be provided, but since no reason exists why the Michael addition should be less efficient in case of St, no further characterization was applied and full end group conversion was assumed. This assumption is well underpinned by the successful coupling reactions described below.

\section{Synthesis of Block Copolymers via Polymer CuAAC Conjugations Reactions in Flow}

With the azidated ATRP polymers and the converted RAFT polymers at hand, the final goal of studying the copper- 

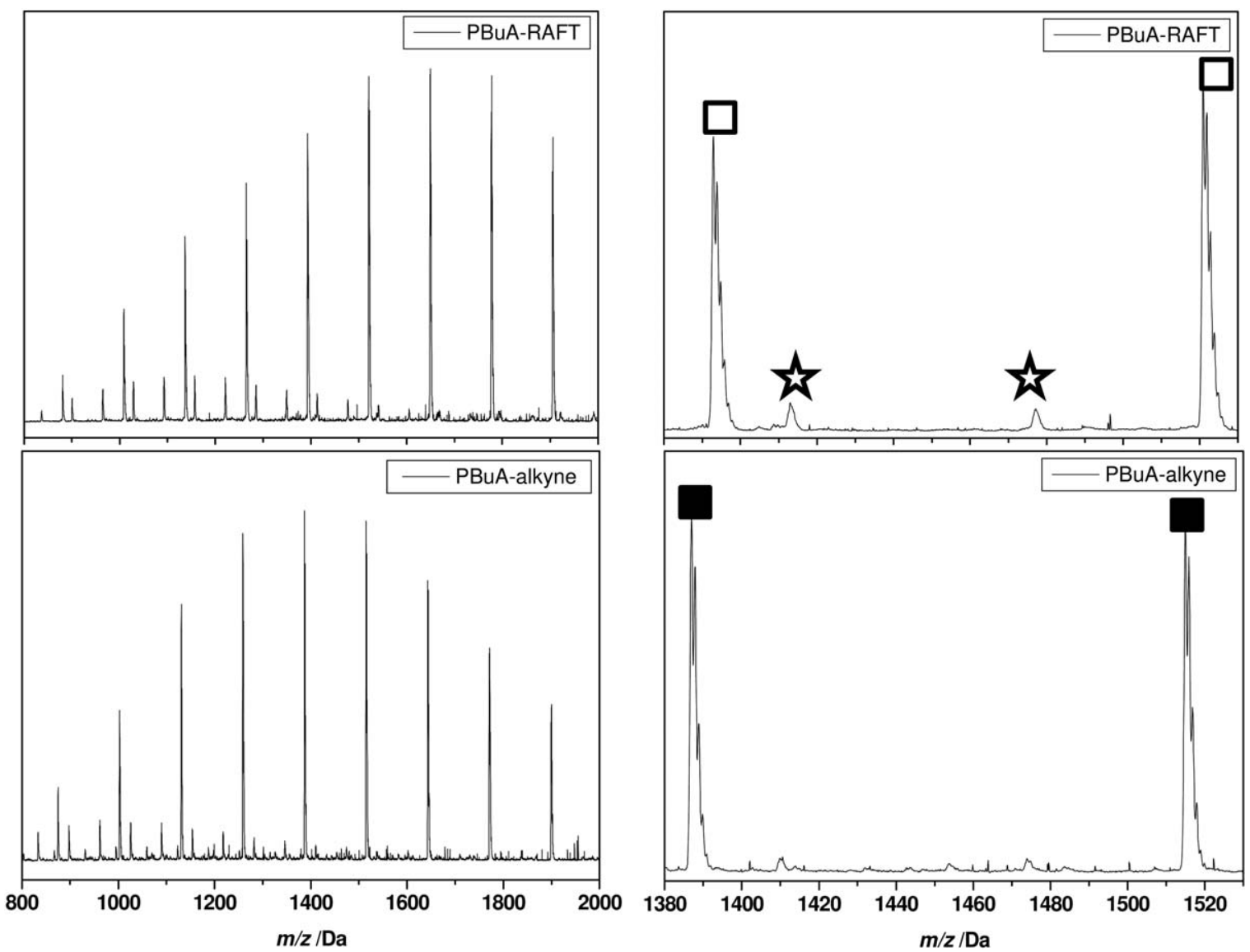

FIGURE 5 ESI-MS spectra of PBuA-RAFT (7) and PBuA-alkyne (10). Left: full MS spectra. Right: spectra of single-monomer repeating units (squares represent single charged species; stars represent double charged species).

catalyzed azide-alkyne coupling reaction under microflow conditions could be targeted. As the azidation of PBuA was confirmed by nearly perfect end group conversion with ESIMS, mostly this polymer was used to study the click reaction with alkyne end-capped counterparts. As a first step, the click reaction between $\mathrm{PBuA}-\mathrm{N}_{3}$ and PBuA-alkyne was studied, both in batch (3 h, R.T.) and in the microreactor to allow for comparison of the two reaction modes. Both polymers were mixed in a one to one molar ratio and dissolved in DMF. A DMF solution containing 1 equivalent of $\mathrm{Cu}(\mathrm{I}) \mathrm{Br}$ and 2 equiv of PMDETA ligand were applied to start the reaction. Unfortunately, all attempts to couple the polymers in the microreactor resulted after more or less short reaction times in reactor fouling and even complete blocking of the microchannels by copper complexes, even though the initial solutions were well homogenous. Formation of precipitates was observed during the reaction at elevated temperatures which might be attributable to disproportionation of the copper species. As a result, a glass chip reactor with a total volume of $2 \mathrm{~mL}$ and an internal channel diameter of $1 \mathrm{~mm}$ was employed. Such bigger reactor did not suffer from channel blocking during the CuAAC reactions under the same reaction conditions since small copper precipitates are able to travel through the channels. Therefore, the bigger reactor was used in all further click experiments.
Figure 7 depicts the SEC elugrams of the azide and alkyne end-capped PBuA polymers and of the resulting PBuA- $b$ PBuA block copolymers, obtained in batch and in flow. The molar masses and dispersities are displayed in Table 3. In both cases, a clear shift of the elugram toward higher molar masses was observed for the conjugated materials. The elugrams correspond well to theoretic expectations for polymer coupling of two distributions of different molar mass. ${ }^{35}$ Furthermore, the use of the pressurized flow reactor allowed for acceleration of the reaction from $3 \mathrm{~h}$ at R.T. (batch) to 40 min at $80{ }^{\circ} \mathrm{C}$ in flow, while retaining full conversion of the reaction. Further acceleration by increasing reaction temperature proved to fail. When temperatures higher than $80^{\circ} \mathrm{C}$ are applied, severe disproportionation of the $\mathrm{Cu}(\mathrm{I}) \mathrm{Br}$ into $\mathrm{Cu}(0)$ and $\mathrm{Cu}(\mathrm{II}) \mathrm{Br}_{2}$ impede the reaction progress and less efficient coupling is observed.

After the successful coupling of the two PBuA polymers in flow, CuAAC click reactions were also performed to synthesize PBuA- $b$-PMMA and PBuA- $b$-PS block copolymers. The results are displayed in Figure 8 , and average molecular weights are given in Table 3 . In all cases, similar shifts in the SEC elugrams were observed, and identical resulting molar masses were obtained for block copolymers synthesized in batch ( 3 h, R.T.) and flow ( $\left.40 \mathrm{~min}, 80^{\circ} \mathrm{C}\right)$. 

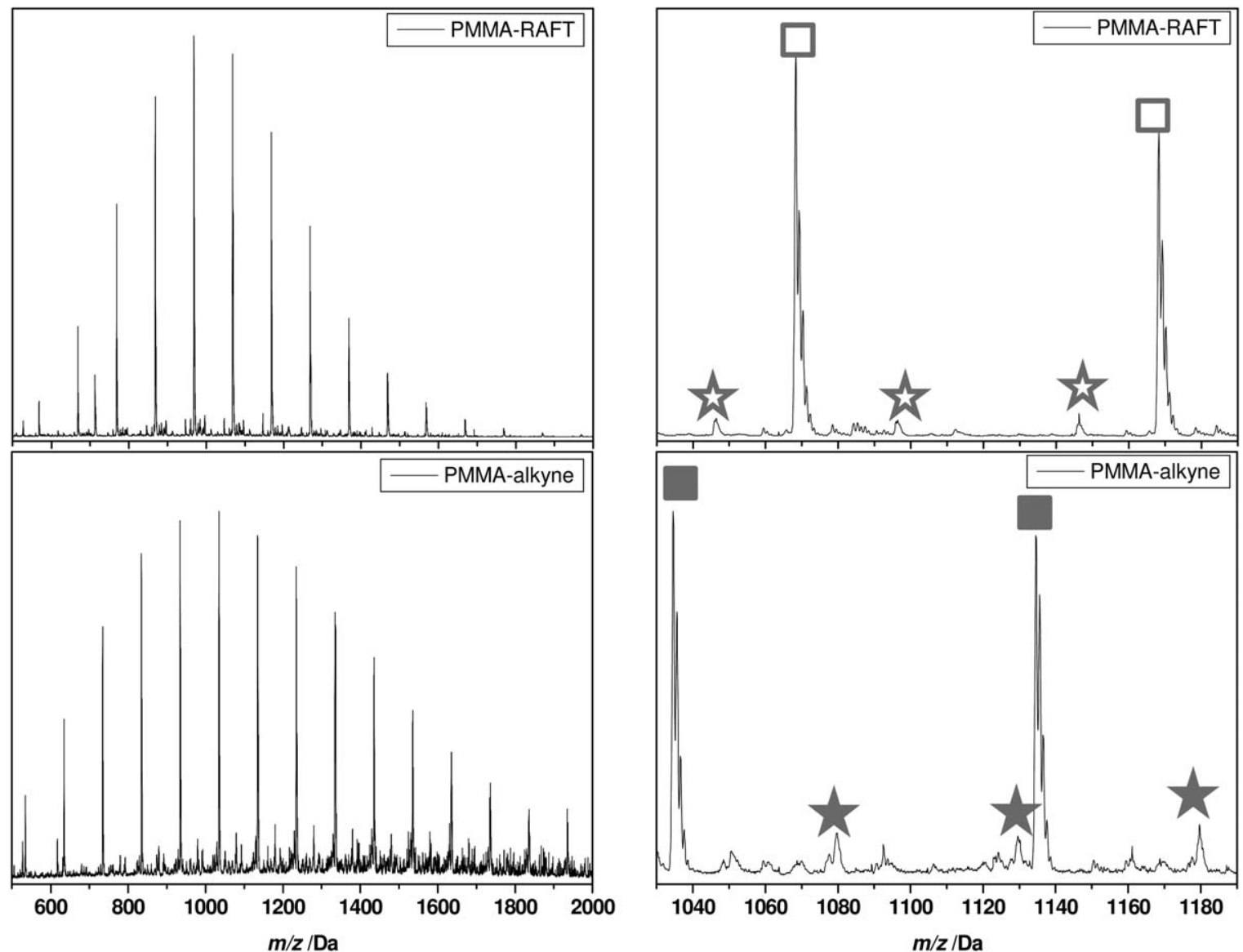

FIGURE 6 ESI-MS spectra of PMMA-RAFT (8) and PMMA-alkyne (11). Left: full MS spectra. Right: spectra of single-monomer repeating units (squares represent single charged species; stars represent double charged species).

Since the formation of PMMA- $\mathrm{N}_{3}$ was only partially successful, this polymer was not used in any further click reaction. $\mathrm{PS}-\mathrm{N}_{3}$ on the other hand, was used in click reactions with alkyne end-capped PBuA, PMMA, and PS. The reactions were first studied in batch. The SEC elugrams of these reactions can be found in the Supporting Information. Unfortunately, those attempts at conjugations were less successful than the ones with $\mathrm{PBuA}-\mathrm{N}_{3}$, and resulted only in partial shifts of the
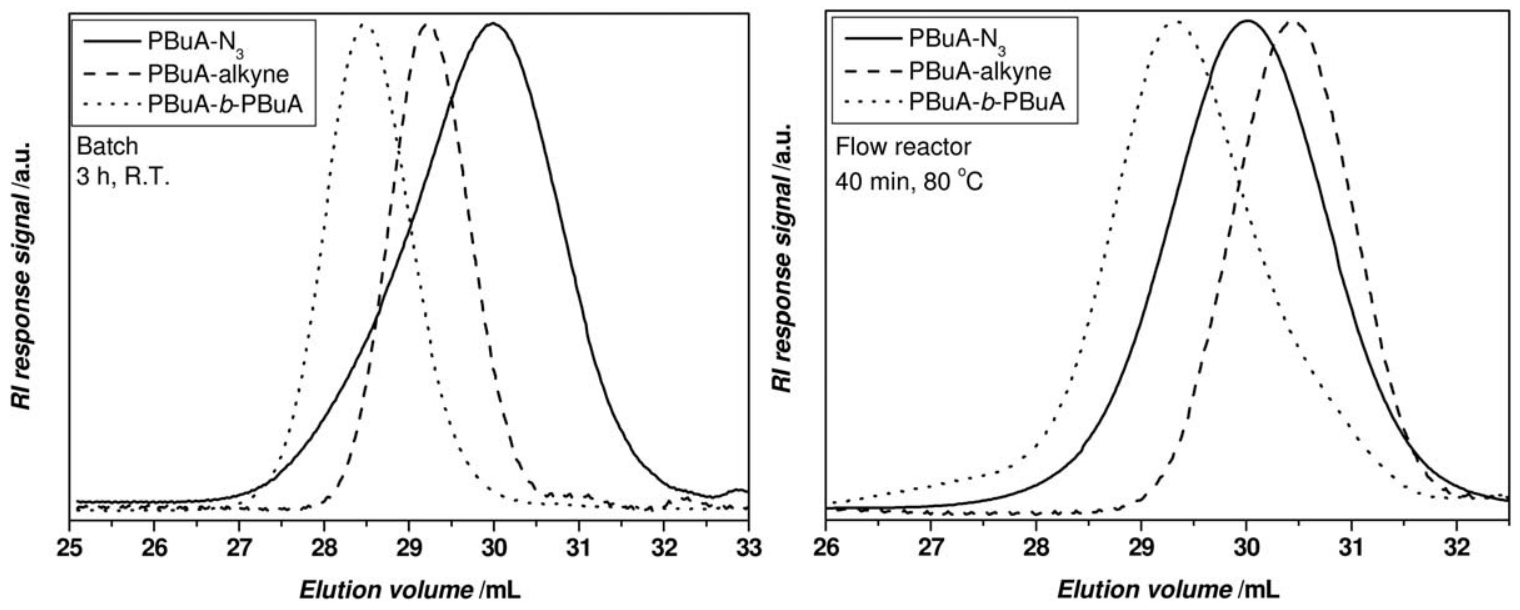

FIGURE 7 SEC elugram of PBuA-N ${ }_{3}$ (4), PBuA-alkyne (10), and clicked polymer PBuA- $b$-PBuA (13B and 13F), after CuAAC click reaction. Left: batch, $3 \mathrm{~h}$, R.T. Right: flow reactor, $40 \mathrm{~min}, 80^{\circ} \mathrm{C}$. (PBuA-alkyne polymers with different molar masses and two different PBuA- $\mathrm{N}_{3}$ batches with identical molar masses were used for batch and flow reaction). 

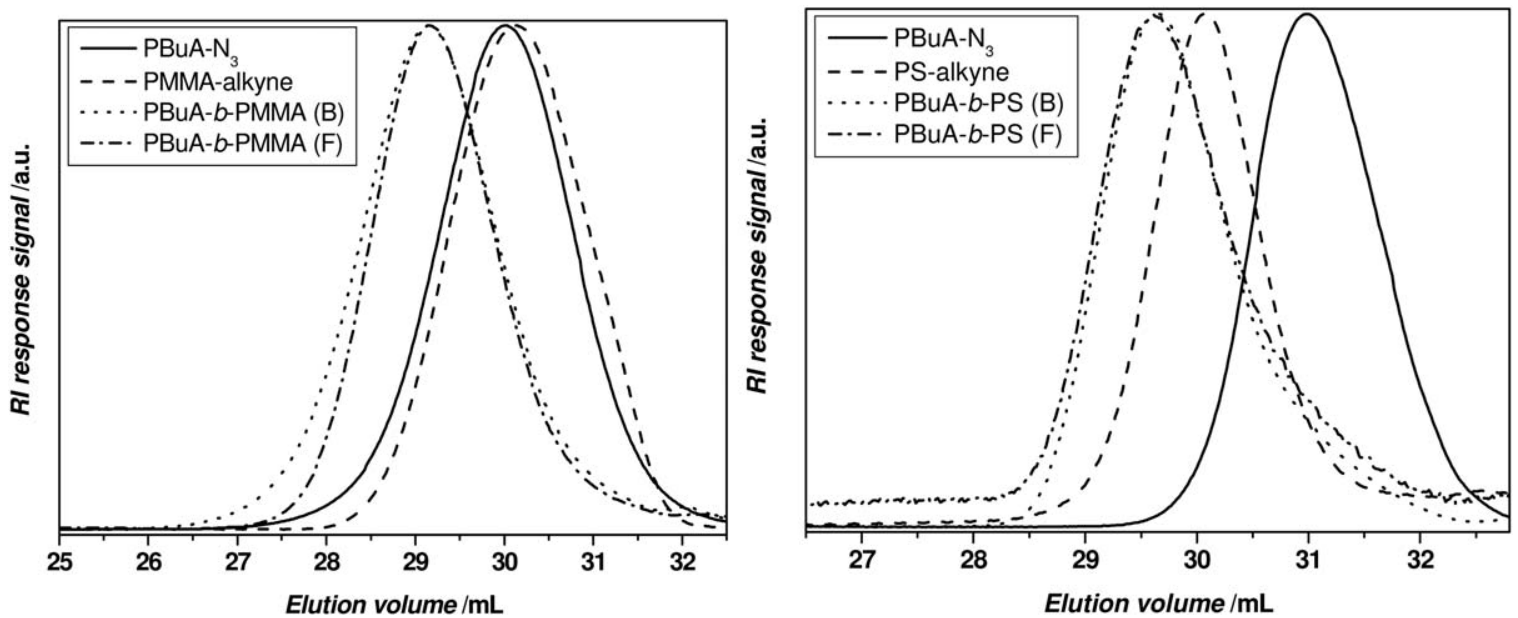

FIGURE 8 Left: SEC elugram of PBuA-N ${ }_{3}$ (4), PMMA-alkyne (11), and clicked polymers PBuA- $b$-PMMA (14B) and PBuA-b-PMMA (14F). Right: SEC elugram of PBuA-N $\mathrm{N}_{3}$ (4), PS-alkyne (12), and clicked polymers PBuA-b-PS (15B) and PBuA-b-PS (15F), after CuAAC click reactions in batch $\left(3 \mathrm{~h}\right.$, R.T.) and in flow reactor $\left(40 \mathrm{~min}, 80^{\circ} \mathrm{C}\right)$.

elugrams, together with low molar mass tailing. Possibly, during the ATRP of PS, a small fraction of the polymer chains terminated, which therefore could not be converted into azide end groups. ESI-MS analysis of PS samples is, however, unsuited to determine the exact end group fidelity (elimination reactions of the end groups occur during the ESI-MS analysis itself). ${ }^{32}$ Consequently, no further attempts were made to perform the click reactions with PS- $\mathrm{N}_{3}$ in the flow reactor. It should be noted though, that-similar to the PMMA system-reactivity of the CuAAC systems is in all likelihood not limited by the flow system, but by the quality of the obtainable azides by the used flow protocol. Application of azides with higher end group fidelity should thus also lead to successful MRT adaptions of the click reaction in future.

\section{CONCLUSIONS}

Successful azidation reactions for poly(butyl acrylate) ATRPmade polymers via TMS- $\mathrm{N}_{3}$ could be established at elevated temperatures $\left(80^{\circ} \mathrm{C}\right)$ by the use of a continuous flow microreactor whereby the reaction could be accelerated from a few hours (in batch) to a few seconds (in the microreactor). Nearly perfect end group conversion was observed by ESIMS. For PMMA, azidation reactions are slower and elimination is observed as a significant side reaction, rendering the synthesis protocol unsuitable for PMMA. For PS quantitative end group conversion was achieved after $60 \mathrm{~s}$ at $100{ }^{\circ} \mathrm{C}$ as indicated by FTIR and ${ }^{1} \mathrm{H}$ NMR spectroscopy.

In a second step, PBuA, PMMA, and PS precursors were synthesized using RAFT polymerization. The trithiocarbonate end groups were successfully converted into alkyne end groups by base-catalyzed aminolysis and subsequent thiolene Michael additions with propargyl acrylate.

Finally, azide end-capped PBuA was coupled with the alkyne end-capped polymers by using a CuAAC click approach in a continuous flow process. In order to avoid copper fouling and blocking of the microreactor channels, a 2-mL glass chip reactor with an internal diameter of $1 \mathrm{~mm}$ was used for these conjugation reactions. Successful coupling reactions were observed in the flow reactor for $\mathrm{PBuA}-b$-PBuA, $\mathrm{PBuA}-b$ PMMA, and PBuA- $b$-PS.

In general, it can be concluded that flow reactor procedures can be used for the complete synthesis of well-defined block copolymers, starting from the polymerization reaction itself, followed by very fast and efficient azide or alkyne end group conversions and finalized by polymer-polymer conjugation reactions. This opens up pathways for efficient upscaling of these procedures and the possibility to provide well-defined polymer materials on industrial scale.

\section{ACKNOWLEDGMENTS}

The authors are grateful for award of the Odysseus project "Precise Polymer Design for the Development of New Materials" by the Fund for Scientific Research-Flanders (FWO). Additional support via the European Science FoundationPrecision Polymer Materials (P2M) program is acknowledged. Also, the authors wish to thank the "Belgian Science Policy" for financial support in the frame of the "Interuniversity Attraction Poles Programme IAP-PAI P7/05" "Functional Supramolecular Systems."

\section{REFERENCES AND NOTES}

1 C. Wiles, P. Watts, Chem. Commun, 2011, 47, 6512-6535.

2 W. Ehrfeld, V. Hessel, H. Löwe, Microreactors: New Technology for Modern Chemistry, Wiley-VCH: Weinheim, 2000.

3 N. T. Nguyen, Z. G. Wu, J. Micromech. Microeng. 2005, 15, R1-R16.

4 G. L. Morini, Int. J. Therm. Sci. 2004, 43, 631-651.

5 K. Jähnisch, V. Hessel, H. Löwe, M. Baerns, Angew. Chem. Int. Ed. 2004, 43, 406-446. 
6 C. Tonhauser, A. Natalello, H. Löwe, H. Frey, Macromolecules 2012, 45, 9551-9570.

7 K. Matyjaszewski, J. Xia, Chem. Rev. 2001, 101, 2921-2990.

8 N. Chan, S. Boutti, M. F. Cunningham, R. A. Hutchinson, Macromol. React. Eng. 2009, 3, 222-231.

9 N. Chan, M. F. Cunningham, R. A. Hutchinson, Macromol. React. Eng. 2010, 4, 369-380.

10 N. Chan, M. F. Cunningham, R. A. Hutchinson, J. Polym. Sci. Part A: Polym. Chem. 2013, 51, 3081-3096.

11 M. Müller, M. F. Cunningham, R. A. Hutchinson, Macromol. React. Eng. 2008, 2, 31-36.

12 C. J. Hawker, A. W. Bosman, E. Harth, Chem. Rev. 2001, $301,3661-3688$.

13 T. Fukuyama, Y. Kajihara, I. Ruy, A. Studer, Synthesis 2012, 44, 2555-2559.

14 J. Chiefari, Y. K. Chong, F. Ercole, J. Krstina, J. Jeffery, T. P. T. Le, R. T. A. Mayadunne, G. F. Meijs, C. L. Moad, G. Moad, E. Rizzardo, S. H. Thang, Macromolecules 1998, 31, 5559-5562.

15 C. H. Hornung, C. Guerrero-Sanchez, M. Brasholz, S. Saubern, J. Chiefari, G. Moad, E. Rizzardo, S. H. Thang, Org. Process Res. Dev. 2011, 15, 593-601.

16 B. M. Rosen, V. Percec, Chem. Rev. 2009, 109, 5069-5119.

17 N. Chan, M. F. Cunningham, R. A. Hutchinson, Macromol. Rapid. Commun. 2011, 32, 604-609.

18 N. Chan, M. F. Cunningham, R. A. Hutchinson, Polym. Chem. 2012, 3, 1322-1333.

19 J. A. Burns, C. Houben, A. Anastasaki, C. Waldron, A. A. Lapkin, D. M. Haddleton, Polym. Chem. 2013, 4, 4809-4813.

20 B. Dervaux, T. Junkers, C. Barner-Kowollik, F. E. Du Prez, Macromol. React. Eng. 2009, 3, 529-538.
21 C. H. Hornung, X. Nguyen, S. Kyi, J. Chiefari, S. Saubern, Aust. J. Chem. 2013, 66, 192-198.

22 C. H. Hornung, A. Postma, S. Saubern, J. Chiefari, Macromol. React. Eng. 2012, 6, 246-251.

$23 \mathrm{~J}$. Vandenbergh, T. Ogawa de Moraes, T. Junkers, J. Polym. Sci. Part A: Polym. Chem. 2013, 51, 2366-2374.

24 J. Vandenbergh, T. Junkers, Polym. Chem. 2012, 3, 27392742.

25 C. Barner-Kowollik, F. E. Du Prez, P. Espeel, C. J. Hawker, T. Junkers, H. Schlaad, W. van Camp, Angew. Chem. Int. Ed. 2011, 50, 60-62.

26 J. Xia, S. G. Gaynor, K. Matyjaszewski, Macromolecules 1998, 31, 5958-5959.

27 J. Vandenbergh, T. Junkers, Macromolecules 2012, 45, $6850-6856$

$28 \mathrm{M}$. Glassner, K. K. Oehlenschlaeger, T. Gruendling, C. Barner-Kowollik, Macromolecules 2011, 44, 4681-4689.

29 K. Matyjaszewski, Y. Nakagawa, S. G. Gaynor, Macromol. Rapid Commun. 1997, 18, 1057-1066.

30 V. Bhadraiah Sadhu, J. Pionteck, D. Voigt, H. Komber, D. Fischer, B. Voit, Macromol. Chem. Phys. 2004, 205, 2356-2365.

31 J. Song, B.-K. Cho, Macromol. Res. 2012, 20, 1037-1043.

32 C. Ladavière, P. Lacroix-Desmazes, F. Delolme, Macromolecules 2009, 42, 70-84.

33 D. Han, X. Tong, Y. Zhao, J. Polym. Sci. Part A: Polym. Chem. 2012, 50, 4198-4205.

34 H. Gao, K. Matyjaszewski, Macromolecules 2006, 39, 49604965.

35 C. Barner-Kowollik, Macromol. Rapid Commun. 2009, 30, 1625-1631. 